\title{
Characterization of linearly coupled capillaries with various inner diameters in the context of capillary electrophoresis
}

\author{
Daniel Böhm ${ }^{1} \cdot$ Frank-Michael Matysik ${ }^{1}$ (D)
}

Received: 28 January 2021 / Accepted: 5 May 2021 / Published online: 10 July 2021

(c) The Author(s) 2021

\begin{abstract}
As a result of continuous instrumental progress, capillary electrophoresis has become an established separation technique. However, the choice of the suitable capillary inner diameter is sometimes difficult due to different instrumental requirements concerning injection, separation, or detection. To overcome this problem, we assembled two capillaries with different inner diameters, meaning that the inner diameter of the capillary at the injection side was different from that at the detection side. Since this was a rather uncommon approach, we focused on the associated effects in this proof-of-concept study. For the experiments, a non-aqueous model system was used, consisting of an acetonitrile-based background electrolyte and the two ferrocene derivates, ferrocenemethanol and decamethylferrocene. Using capillary flow injection analysis hyphenated to capacitively coupled contactless conductivity detection, it could be shown that fragmented capillaries of the same inner diameter had slightly lower volume flow rates than non-fragmented capillaries. With non-aqueous capillary electrophoresis hyphenated to UV detection, it was found that the coupling of capillaries with different inner diameter had a much stronger effect on the capillary electrophoresis flow than combinations with the same inner diameter. Additionally, if the inner diameter of the second capillary was larger than the inner diameter of the first capillary, a higher theoretical plate number and an increased sensitivity were found. Furthermore, it was found that there was no significant peak tailing introduced by the coupling.
\end{abstract}

\section{Graphic abstract}

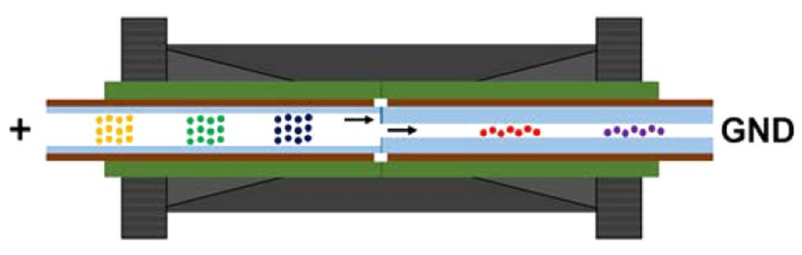

Keywords Capillary flow injection analysis · Capillary zone electrophoresis · Coupled fused silica capillaries ·

Electrochemistry $\cdot$ Organometallic compounds

\section{Introduction}

Capillary electrophoresis (CE) is a powerful separation technique due to its high separation efficiency, the low sample consumption, and its high separation speed. Thus, the field of $\mathrm{CE}$ is still in instrumental progress [1-3]. In recent years,

Frank-Michael Matysik

Frank-Michael.Matysik@chemie.uni-regensburg.de

1 Institute of Analytical Chemistry, Chemo- and Biosensors, University of Regensburg, Regensburg, Germany different injection methods were developed and CE was hyphenated to various detectors $[4,5]$. However, choosing the suitable capillary inner diameter (ID) is sometimes difficult. Capillaries with small IDs are for example interesting for small amounts of sample and high separation efficiency due to lower Joule heating $[4,6,7]$. In contrast, capillaries with larger IDs are preferred for example for on-column $\mathrm{UV} / \mathrm{Vis}$ detection to generate a better sensitivity due to extended optical path lengths $[4,8]$. These are just a few examples which show that different applications require 
various capillary IDs. When injection, separation or detection aspects suggest the use of different capillary ID, often a compromise has to be found. We tried to overcome this problem by the combination of two capillaries with various IDs.

The coupling of capillaries is already described in literature but predominately in the context of 2D separations. In these cases, the capillaries were coupled with valves or micro-structured chips [9-13]. These approaches were not suitable for our application because we intended to have a continuous CE separation without decoupling from the high voltage field and a straightforward combination of conventional capillaries. There are other cases where capillaries with different IDs were coupled to achieve fast electrophoretic separations [14-16]. However, in these studies, injection and detection were performed in capillary segments of identical ID. Horká et al. [17] used capillaries with different IDs produced by etching for online sample pre-concentration. In most of the previously mentioned cases, the capillaries were irreversibly connected. In our approach, a commercially available capillary connector was used, which allowed for exchanging of capillaries and nearly dead volume-free coupling. Additionally, injection and detection were performed on opposite ends of the linearly coupled capillaries.

In the frame of this contribution, we investigated the linear coupling of capillaries with various IDs, meaning that the ID of the capillary at the injection side was different from that at the detection side. The resulting effects were investigated with capillary flow injection analysis hyphenated to capacitively coupled contactless conductivity detection (CFIA- ${ }^{4} \mathrm{D}$ ) and $\mathrm{CE}$ hyphenated to UV detection (CE-UV).

\section{Results and discussion}

\section{CFIA-C $C^{4} D$ experiments}

The measurements were performed with a model system containing decamethylferrocene ( $\mathrm{dMFc}$ ) as analyte and a non-aqueous, acetonitrile-based background electrolyte (BGE) as carrier solution. This model system was chosen due to the good UV transparency and the stable electroosmotic flow. Additionally, in future projects, it is planned to utilize the concept of coupled capillaries in combination with an amperometric detector, where the acetonitrile-based BGE is favorable due to the electrochemical characteristics $[4,18]$.

The CFIA-C $\mathrm{C}^{4} \mathrm{D}$ experiments in this project were performed to study the effects associated with capillary coupling under conditions of a gravity-driven flow system. The volume flow rates (VFRs) and the corresponding standard deviations (SDs) shown in Table 1 for a height difference of
Table 1 CFIA-C ${ }^{4} \mathrm{D}$ studies for the determination of the VFRs and the corresponding SDs $(n=4)$ of non-fragmented and fragmented capillaries for a height difference between inlet and outlet vial of $20 \mathrm{~cm}$

\begin{tabular}{lll}
\hline $\begin{array}{l}\text { Capillary combina- } \\
\text { tion/ } \mu \mathrm{m}\end{array}$ & $\mathrm{VFR} / 10^{-9} \mathrm{dm}^{3} / \mathrm{s}$ & $\pm \mathrm{SD} / 10^{-9} \mathrm{dm}^{3} / \mathrm{s}$ \\
\hline 25 & 0.0577 & 0.0005 \\
$25+25$ & 0.057 & 0.001 \\
$50+25$ & 0.0775 & 0.0007 \\
$75+25$ & $-^{\mathrm{a}}$ & $-^{\mathrm{a}}$ \\
$25+50$ & 0.137 & 0.005 \\
50 & 0.865 & 0.002 \\
$50+50$ & 0.80 & 0.05 \\
$75+50$ & 1.05 & 0.06 \\
$25+75$ & 0.187 & 0.002 \\
$50+75$ & 1.941 & 0.003 \\
75 & 4.56 & 0.02 \\
$75+75$ & 4.2 & 0.1 \\
\hline
\end{tabular}

Experimental conditions: sample solution $10 \mathrm{mmol} / \mathrm{dm}^{3} \mathrm{dMFc}$ in BGE, capillary length $70 \mathrm{~cm}(40 \mathrm{~cm}$ to the detector, fragmented capillaries: $20 \mathrm{~cm}$ first part and $50 \mathrm{~cm}$ second part), injection time $5 \mathrm{~s}$ and BGE (10 mmol/dm $\mathrm{dm}_{4} \mathrm{OAc}$ and $1 \mathrm{~mol} / \mathrm{dm}^{3} \mathrm{HOAc}$ in $\left.\mathrm{ACN}\right)$ as carrier solution

${ }^{\mathrm{a}}$ For the capillary combination $75+25 \mu \mathrm{m}$, no VFR could be determined due to bubble formation

$20 \mathrm{~cm}$ were calculated based on four CFIA-C $\mathrm{C}^{4} \mathrm{D}$ measurements. It should be noted that different linear flow velocities were present in different segments of the fragmented capillaries with various IDs. Therefore, we used the VFRs which were the same over the entire length of the capillary. It was found that the VFRs were slightly lower for fragmented capillaries compared to non-fragmented capillaries of the same dimension. This indicates that a small additional flow resistance arises when two capillaries are combined. Furthermore, it was found that the VFR decreases for upstream capillaries with lower IDs and vice versa. The VFR for the combination $75+25 \mu \mathrm{m}$ could not be determined. We assume this was due to the formation of air bubbles at the connection site, indicated by an enormous increase in the electrical resistance. The VFRs were used for the calculations of the injection times for an $0.35 \mathrm{~cm}$ long injection segment in the CE-UV experiments.

\section{CE-UV experiments}

Figure 1 shows in the upper part the electropherograms of the non-fragmented capillaries with IDs of 25, 50, and $75 \mu \mathrm{m}$ and in the lower part the electropherograms of the capillary combinations with a downstream $50 \mu \mathrm{m}$ capillary segment $(25+50,50+50$, and $75+50 \mu \mathrm{m})$. Prior to the detailed discussion, it has to be mentioned the neutral ferrocenemethanol $(\mathrm{FcMeOH})$ served as electroosmotic flow (EOF) marker while dMFc served as cationic model 

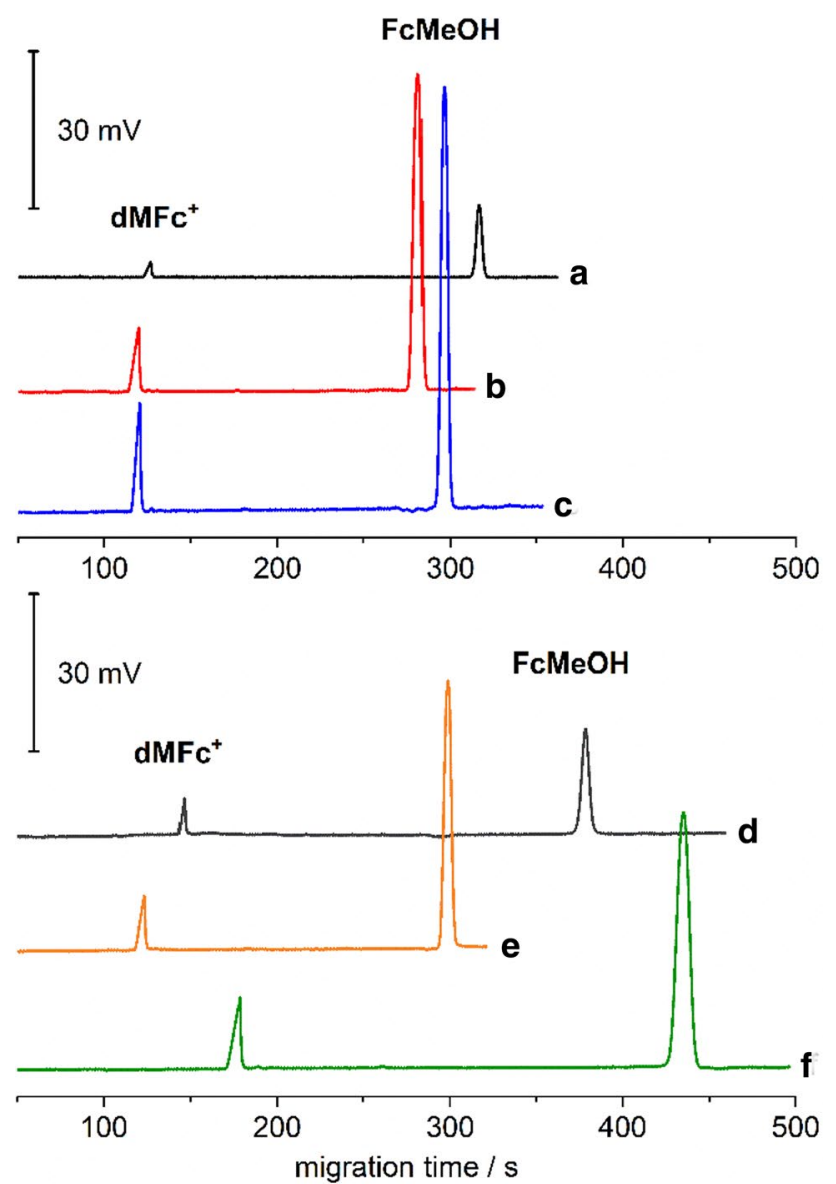

Fig. 1 Electropherograms of the model mixture $\mathrm{FcMeOH} / \mathrm{dMFc}$ measured with non-fragmented (top) and fragmented capillaries (bottom) of different IDs: 25 (a), 50 (b), $75 \mu \mathrm{m}$ (c), $25+50 \mu \mathrm{m}$ (d), $50+50 \mu \mathrm{m}(\mathbf{e})$, and $75+50$ (f). Experimental parameters: $1 \mathrm{mmol} /$ $\mathrm{dm}^{3} \mathrm{FcMeOH}$ and dMFc in BGE $\left(10 \mathrm{mmol} / \mathrm{dm}^{3} \mathrm{NH}_{4} \mathrm{OAc}\right.$ and $1 \mathrm{~mol} /$ $\mathrm{dm}^{3} \mathrm{HOAc}$ in $\left.\mathrm{ACN}\right)$. Injection segment $0.35 \mathrm{~cm}$, separation voltage $25 \mathrm{kV}$, capillary length $70 \mathrm{~cm}(40 \mathrm{~cm}$ to the detector, fragmented capillaries: $20 \mathrm{~cm}$ first part and $50 \mathrm{~cm}$ second part), UV detection at $210 \mathrm{~nm}$. The BGE levels in the inlet and outlet vial were at the same height

analyte since it is easily oxidized by dissolved oxygen in solution [19]. The BGE levels in the inlet and outlet reservoirs were at the same height. Therefore, there was no gravity-driven flow. The measurements performed with nonfragmented capillaries had nearly the same migration times for the cationic $\left(\mathrm{dMFc}^{+}\right)$and the neutral species $(\mathrm{FcMeOH})$, independent of the ID. The averaged migration times and the corresponding SDs for the non-fragmented and fragmented capillaries are listed in Table 2. Since the electrophoretic and the EOF migration contribute to the overall migration time of the $\mathrm{dMFc}^{+}$, we calculated the apparent mobility of $\operatorname{dMFc}^{+}\left(\mu_{a}\right)$, the EOF mobility of FcMeOH $\left(\mu_{\mathrm{EOF}}\right)$, and the effective mobility of $\mathrm{dMFc}^{+}\left(\mu_{\text {eff }}\right)$ to separate these effects. Due to the very similar migration times for the non-fragmented capillaries $(25,50$, and $75 \mu \mathrm{m})$, the mobilities were nearly the same. The relative standard deviations for the mobilities of the non-fragmented capillaries with different IDs were $3 \%$ for $\mu_{a}, 6 \%$ for $\mu_{\mathrm{EOF}}$ and $2 \%$ for $\mu_{\text {eff }}(n=9)$. The calculated mobilities $\left(\mu_{a}, \mu_{\mathrm{EOF}}\right.$, and $\left.\mu_{\mathrm{eff}}\right)$ and the corresponding SDs for the different capillary combinations are summarized in Table 3.

The electropherograms for the capillary combinations with a downstream $50 \mu \mathrm{m}$ capillary segment $(25+50$, $50+50$, and $75+50 \mu \mathrm{m}$ ) are presented in the lower part of Fig. 1. For the combination $50+50 \mu \mathrm{m}$, the migration times were $4 \%$ higher for the cationic $\left(\mathrm{dMFc}^{+}\right)$and $7 \%$ higher for the neutral species $(\mathrm{FcMeOH})$ compared to the non-fragmented $50 \mu \mathrm{m}$ capillary. Looking at the mobilities, it was found that $\mu_{E O F}$ was $8 \%$ and $\mu_{\text {eff }}$ was $1 \%$ lower for the fragmented capillary $(50+50 \mu \mathrm{m})$. Therefore, the coupling of two identical capillaries predominately affected the EOF. The reduction of the EOF was probably due to a flow resistance at the connection site, which was also found for the CFIA-C ${ }^{4} \mathrm{D}$ experiments.

In contrast to the combination of capillaries with the same ID, a considerable shift of the migration times and the corresponding mobilities was found for the fragmented capillaries with different IDs $(25+50$ and $75+50 \mu \mathrm{m})$. Since $\mu_{\mathrm{EOF}}$ and $\mu_{\text {eff }}$ were significantly lower for fragmented capillaries with different ID, it can be concluded that the coupling influenced the EOF and the migration of the cationic species. It is important to note that in the present case, $\mu_{\text {eff }}$ does
Table 2 CE-UV studies for the determination of the migration times for $\mathrm{dMFc}^{+}$and $\mathrm{FcMeOH}$, the measured electrophoretic currents and the corresponding SDs $(n=3)$ of non-fragmented and fragmented capillaries

\begin{tabular}{|c|c|c|c|c|c|c|}
\hline $\begin{array}{l}\text { Capillary com- } \\
\text { bination/ } \mu \mathrm{m}\end{array}$ & $\begin{array}{l}\text { Migration time } \\
\mathrm{dMFc}^{+} / \mathrm{s}\end{array}$ & $\pm \mathrm{SD} / \mathrm{s}$ & $\begin{array}{l}\text { Migration time } \\
\mathrm{FcMeOH} / \mathrm{s}\end{array}$ & $\pm \mathrm{SD} / \mathrm{s}$ & $\begin{array}{l}\text { Electrophoretic } \\
\text { current/ } \mu \mathrm{A}\end{array}$ & $\pm \mathrm{SD} / \mu \mathrm{A}$ \\
\hline 25 & 128 & 1 & 319 & 2 & 1.42 & 0.01 \\
\hline 50 & 120.1 & 0.9 & 281 & 3 & 3.98 & 0.09 \\
\hline 75 & 120.7 & 0.2 & 295 & 1 & 9.7 & 0.1 \\
\hline $25+50$ & 146.3 & 0.3 & 379 & 1 & 2.92 & 0.08 \\
\hline $50+50$ & 124 & 2 & 300 & 3 & 4.02 & 0.01 \\
\hline $75+50$ & 180 & 1 & 439 & 4 & 4.84 & 0.08 \\
\hline
\end{tabular}

Experimental conditions: $1 \mathrm{mmol} / \mathrm{dm}^{3} \mathrm{FcMeOH}$ and dMFc in BGE $\left(10 \mathrm{mmol} / \mathrm{dm}^{3} \mathrm{NH}_{4} \mathrm{OAc}\right.$ and $1 \mathrm{mmol} /$ $\mathrm{dm}^{3} \mathrm{HOAc}$ in ACN), injection segment $0.35 \mathrm{~cm}$, separation voltage $25 \mathrm{kV}$, capillary length $70 \mathrm{~cm}(40 \mathrm{~cm}$ to the detector, fragmented capillaries: $20 \mathrm{~cm}$ first part and $50 \mathrm{~cm}$ second part), $\mathrm{UV}$ detection at $210 \mathrm{~nm}$ 
Table 3 Calculated mobilities $\mu_{a}$ for $\mathrm{dMFc}^{+}, \mu_{\mathrm{EOF}}$ for $\mathrm{FcMeOH}, \mu_{\mathrm{eff}}$ for $\mathrm{dMFc}^{+}$, and the corresponding SDs $(n=3)$ of non-fragmented and fragmented capillaries based on the CE-UV experiments

\begin{tabular}{lllllll}
\hline $\begin{array}{l}\text { Capillary } \\
\text { combination/ } \\
\mu \mathrm{m}\end{array}$ & $\begin{array}{l}\mu_{a} \mathrm{dMFc}^{+} / \\
\mathrm{cm}^{2} \mathrm{kV}^{-1} \mathrm{~s}^{-1 \mathrm{a}}\end{array}$ & $\begin{array}{l} \pm \mathrm{SD} / \mathrm{cm}^{2} \\
\mathrm{kV}^{-1} \mathrm{~s}^{-1}\end{array}$ & $\begin{array}{l}\mu_{\mathrm{EOF}} \\
\mathrm{FcMeOH} / \\
\mathrm{cm}^{2} \mathrm{kV}^{-1} \mathrm{~s}^{-1} \mathrm{~b}\end{array}$ & $\begin{array}{l} \pm \mathrm{SD} / \\
\mathrm{cm}^{2} \mathrm{kV}^{-1} \mathrm{~s}^{-1}\end{array}$ & $\begin{array}{l}\mu_{\mathrm{eff}} \\
\mathrm{MFFc}^{+} / \\
\mathrm{cm}^{2} \mathrm{kV}^{-1} \mathrm{~s}^{-1 \mathrm{c}}\end{array}$ & $\begin{array}{l} \pm \mathrm{SD} / \\
\mathrm{cm}^{2} \mathrm{kV}^{-1} \mathrm{~s}^{-1}\end{array}$ \\
\hline 25 & 0.873 & 0.008 & 0.351 & 0.002 & 0.522 & 0.006 \\
50 & 0.933 & 0.007 & 0.398 & 0.005 & 0.535 & 0.002 \\
75 & 0.928 & 0.001 & 0.380 & 0.002 & 0.5484 & 0.0006 \\
$50+50$ & 0.765 & 0.002 & 0.295 & 0.001 & 0.4701 & 0.0008 \\
$75+50$ & 0.90 & 0.01 & 0.374 & 0.004 & 0.527 & 0.007 \\
\hline
\end{tabular}

${ }^{\mathrm{a}} \mu_{a}$ was calculated according to the equation $\mu_{a}=(l L) /\left(t_{a} V\right)$, where $l$ was the effective capillary length to the detector, $L$ was the total capillary length, $t_{a}$ the migration time of the analyte ion, and $V$ the applied voltage [20]

${ }^{\mathrm{b}} \mu_{E O F}$ was calculated according to the equation $\mu_{\mathrm{EOF}}=(l L) /\left(t_{\mathrm{EOF}} V\right)$, where $t_{\mathrm{EOF}}$ was the migration time of the EOF marker [20]

${ }^{\mathrm{c}} \mu_{\text {eff }}$ was calculated according to the equation $\mu_{\mathrm{eff}}=\mu_{a}-\mu_{\mathrm{EOF}}[20]$

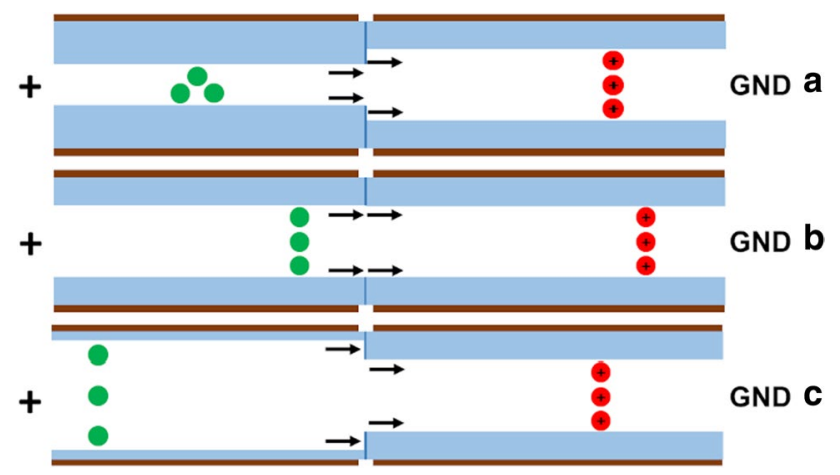

Fig. 2 Scheme of the capillary combinations with a downstream $50 \mu \mathrm{m}$ capillary at the connection site: $25+50(\mathbf{a}), 50+50(\mathbf{b})$, and $75+50 \mu \mathrm{m}$ (c). Especially for the capillary combination $75+50 \mu \mathrm{m}$, the $\mathrm{CE}$ flow was hindered by the downstream smaller capillary

not represent the conventional electrophoretic mobility but includes a contribution which can be attributed to influences of the flow due to the coupling. In our opinion, the lower mobilities were related to the disturbance of the CE flow at the connection site. The CE flow was slightly affected by the coupling of capillaries with the same ID $(50+50 \mu \mathrm{m})$ which resulted in no significant changes in the mobilities, especially for $\mu_{\text {eff }}$. However, the CE flow was strongly influenced by the coupling of capillaries with different IDs which resulted in a significant change in the mobilities.

Figure 2 illustrates the connection region of the capillary combinations $(25+50,50+50$, and $75+50 \mu \mathrm{m})$. Comparing the capillary combinations $25+50 \mu \mathrm{m}$ and $50+50 \mu \mathrm{m}$, it was found that the former yielded $\mu_{a}, \mu_{\mathrm{EOF}}$, and $\mu_{\mathrm{eff}}$ that were 15,21 , and $11 \%$ lower, respectively. However, for the capillary combination $75+50 \mu \mathrm{m}, \mu_{a}, \mu_{\mathrm{EOF}}$, and $\mu_{\mathrm{eff}}$ were 31 , 32 , and $30 \%$ lower compared to the capillary combination $50+50 \mu \mathrm{m}$. Figure 2 shows the hindrance of the $\mathrm{CE}$ flow for the combination $75+50 \mu \mathrm{m}$ by the narrower downstream capillary. This explains why the species for the combination $75+50 \mu \mathrm{m}$ showed lower mobilities in comparison to the capillary combination $25+50 \mu \mathrm{m}$.

To prove this hypothesis, CE-UV experiments with the inverted capillaries (upstream $50 \mu \mathrm{m}$ capillary and downstream 25,50 , or $75 \mu \mathrm{m}$ capillary) were made. According to the hypothesis, the capillary combination $50+25 \mu \mathrm{m}$ should have the lowest mobilities, because in this configuration, the CE flow hits the front surface of the $25 \mu \mathrm{m}$ capillary. The CE-UV experiments with the reverse capillary combinations confirmed this assumption because the lowest mobilities were found for the capillary combination $50+25 \mu \mathrm{m}$ (electropherograms not shown). Based on these experiments, it can be concluded that the coupling influenced the CE flow due to a mechanical hindrance at the connection site. Especially for capillary combinations starting from a larger capillary ID and going to a smaller ID, a decrease of the mobilities was found.

Another striking point was that the peak areas for the combination $25+50 \mu \mathrm{m}$ were about 2 times higher than the peak areas for the non-fragmented $25 \mu \mathrm{m}$ capillary, although the same injection volume was applied in both cases (electropherograms shown in Fig. 1). This can be explained by Lambert-Beer law because with a downstream $50 \mu \mathrm{m}$ capillary the layer thickness is two times higher than with a $25 \mu \mathrm{m}$ capillary. Additionally, the lower linear flow velocity in the downstream $50 \mu \mathrm{m}$ capillary compared to the upstream $25 \mu \mathrm{m}$ capillary contributed to the increased peak areas. Due to the slower linear flow velocity, the analytes spent more time in the detection window, which led to higher peak areas.

Furthermore, it was demonstrated that all peaks showed nearly Gaussian shape and for all combinations there was only negligible peak tailing. Additionally, there was an increase of the theoretical plate number found for the capillary combinations starting from a smaller ID and going to a 
larger ID. The theoretical plate numbers for the $\mathrm{dMFc}^{+}$and $\mathrm{FcMeOH}$ peak were $27 \times 10^{3} \pm 3 \times 10^{3}$ and $28 \times 10^{3} \pm 5 \times 10^{3}$ for the capillary combination $25+50 \mu \mathrm{m}$ while the theoretical plate numbers for the non-fragmented $50 \mu \mathrm{m}$ capillary were $81 \times 10^{2} \pm 3 \times 10^{2}$ for $\mathrm{dMFc}^{+}$and $206 \times 10^{2} \pm 9 \times 10^{2}$ for $\mathrm{FcMeOH}$. This resulted from a compression of the peaks at the transition between a capillary starting with a smaller ID and going to a capillary with a larger ID. This effect could be explained with the different linear flow velocities in the capillary combination $25+50 \mu \mathrm{m}$. The linear flow rate in the upstream $25 \mu \mathrm{m}$ capillary was higher than the linear flow velocity in the downstream $50 \mu \mathrm{m}$ capillary, which led to the compression of the peaks at the connection site.

We tried to visualize this by the behavior of a dye plug at the connection site between a capillary with a smaller and a larger ID. For this purpose, a transparent capillary connector was fabricated. Figure 3 shows a series of microscopic images from a dye plug at the connection site between a 25 and $75 \mu \mathrm{m}$ capillary. Figure $3 \mathrm{c}$ shows the long dye segment in the $25 \mu \mathrm{m}$ capillary which shortens at the transition to the $75 \mu \mathrm{m}$ capillary. The microscopic image $3 \mathrm{e}$ shows the compressed dye plug in the $75 \mu \mathrm{m}$ capillary piece. Even if this experiment was performed by a simple CFIA setup, it could explain the increase of the theoretical plate number by the compression of the peaks at the connection site.

\section{Conclusion}

To overcome the problem of choosing the best-suited capillary ID for injection, separation, or detection in CE, the concept of fragmented capillaries with various IDs was introduced and a proof-of-concept study was carried out. With this approach, it is possible to select the ideal capillary ID combination for the respective application.
With the findings listed in this manuscript, the questions pointed out in the introduction could be clarified. It could be shown that CE measurements with linearly coupled capillaries of various IDs could be realized. Additionally, an increased sensitivity was found for on-column UV detection for the capillary combination $25+50 \mu \mathrm{m}$, due to the extended optical path length. The same capillary combination $(25+50 \mu \mathrm{m})$ showed also a higher theoretical plate number than a non-fragmented $50 \mu \mathrm{m}$ capillary. Contrary to expectations, no significant changes in the peak shape or peak tailing were found for capillary combinations with the same or different IDs. From the CFIA and the $\mathrm{CE}$ measurements, it could be concluded that there was a mechanical disturbance of the flow due to the coupling. Unlike the capillary combination with the same ID, a shift towards lower mobilities was found for capillary combinations starting from a larger ID and going to a smaller ID which was a drawback of fragmented capillaries.

Based on the results described in this manuscript, it can be concluded that the concept of linearly coupled capillaries with various IDs could be established. Therefore, it is possible to combine two capillaries with different IDs to adapt capillary dimensions to the respective injection, separation, or detection requirements.

\section{Experimental}

The following chemicals were used, all of analytical grade: ferrocenemethanol and decamethylferrocene (purity 99\%, ABCR, Karlsruhe, Germany), acetonitrile (ACN), ammonium acetate $\left(\mathrm{NH}_{4} \mathrm{OAc}\right), 0.1 \mathrm{~mol} / \mathrm{dm}^{3}$ sodium hydroxide solution, ultrapure water provided by a Milli Q Advantage A10 system (Merck, Darmstadt Germany),
Fig. 3 Subsequently recorded microscopic images (a-e) showing the behavior of a dye plug at the connection site between a 25 (left side) and a $75 \mu \mathrm{m}$ (right side) capillary. The photos show the compression of the dye plug at the transition between a capillary with a smaller and a capillary with a larger ID. Experimental parameters: dye solution (methylene blue in BGE), the flow was gravitydriven by BGE $\left(10 \mathrm{mmol} / \mathrm{dm}^{3}\right.$ $\mathrm{NH}_{4} \mathrm{OAc}$ and $1 \mathrm{mmol} / \mathrm{dm}^{3}$ $\mathrm{HOAc}$ in $\mathrm{ACN}$ )

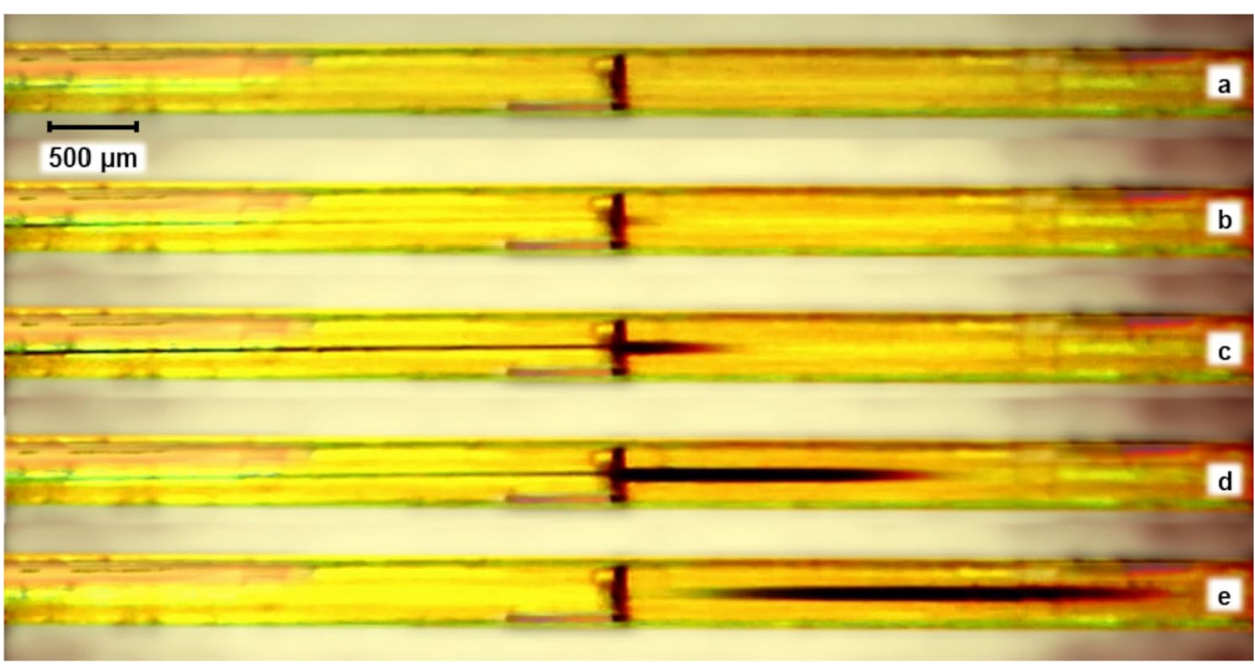


acetic acid (HOAc; Roth, Karlsruhe, Germany), methylene blue (Riedel-de Haën, Seelze, Germany).

\section{Capillaries}

For both experiments (CFIA-C ${ }^{4} \mathrm{D}$ and CE-UV), capillaries with IDs of 25, 50, and $75 \mu \mathrm{m}$, an outer diameter of $360 \mu \mathrm{m}$, and a total length of $70 \mathrm{~cm}$ were used. They were purchased from Polymicro Technologies (Phoenix, USA). Measurements were carried out with fragmented and non-fragmented capillaries. For the measurements with the fragmented capillaries, the original capillaries were cut into two pieces (20 and $50 \mathrm{~cm}$ ) yielding a total of 9 possible capillary combinations with a total length of $70 \mathrm{~cm}(20 \mathrm{~cm}$ first capillary piece and $50 \mathrm{~cm}$ second capillary piece). These combinations are summarized in Table 1. At both ends of the capillaries, about $2 \mathrm{~mm}$ of the polyimide coating was removed to avoid a dead volume introduced by polyimide swelling. To enable a nearly dead volume-free coupling, both sides of the capillary pieces were polished to receive planar capillary tips. For the linear assembling of the capillaries, both capillary pieces were placed in Micro Tight Sleeves F 185 and linearly assembled in a capillary connector called Union Assembly Micro Tight P 720 both from IDEX Health \& Science (Oak Harbor, USA). The installation of the capillaries was carried out according to the user manual of the capillary connector. A detailed scheme of the two capillaries assembled in the capillary connector is shown in Fig. 4. Before the first $\mathrm{CE}$ measurements, the capillaries were preconditioned by flushing them for $10 \mathrm{~min}$ with $0.1 \mathrm{~mol} / \mathrm{dm}^{3}$ sodium hydroxide solution, afterwards for 5 min with ultrapure water, and in the end for $30 \mathrm{~min}$ with $\mathrm{BGE}\left(10 \mathrm{mmol} / \mathrm{dm}^{3} \mathrm{NH}_{4} \mathrm{OAc}\right.$, $1 \mathrm{~mol} / \mathrm{dm}^{3} \mathrm{HOAc}$ in $\mathrm{ACN}$ ).

\section{CFIA-C ${ }^{4} D$ setup}

The VFRs for the fragmented and non-fragmented capillaries were determined with a CFIA-C ${ }^{4} D$ setup schematically depicted in Fig. 5. The concept of CFIA with gravity-driven

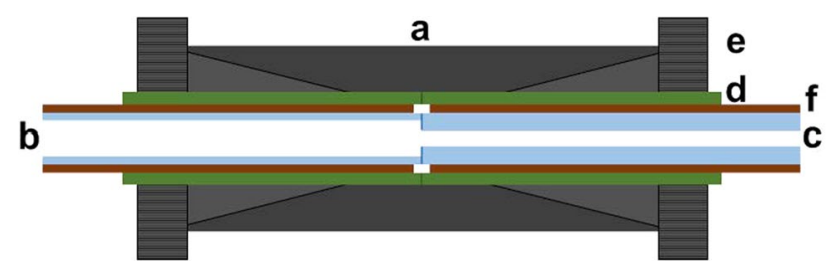

Fig. 4 Scheme of the cross-sectional view of the capillary connector (a). Two capillaries with different IDs (b and c) are coupled without dead volume. The capillaries were placed in sleeves (d) and attached with screws (e). Additionally, about $2 \mathrm{~mm}$ of the polyimide (f) was removed at the connection side to avoid dead volume due to polyimide swelling

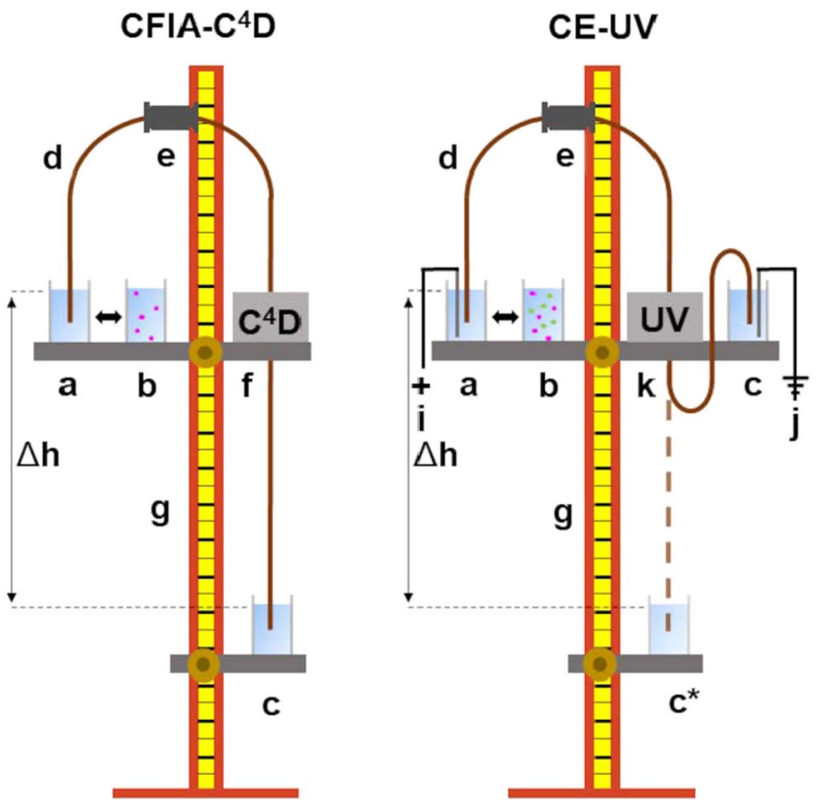

Fig. 5 Scheme of the CFIA-C ${ }^{4}$ D setup (left side) and the CE-UV setup (right side). Components of the CFIA-C ${ }^{4} \mathrm{D}$ setup: sample (a), inlet (b) and outlet BGE vial (c), fused silica capillary (d), linear capillary connector $(\mathbf{e}), \mathrm{C}^{4} \mathrm{D}(\mathbf{f})$ and stand $(\mathbf{g})$. The capillary flow was gravity-driven by a permanent height difference $\Delta h$ between the inlet and outlet reservoir. Components of the CE-UV setup: High voltage supply (i), grounding (j) and UV detector $(\mathbf{k})$. The rest of the components were identical to the CFIA- $\mathrm{C}^{4} \mathrm{D}$ setup. The outlet buffer vial was lowered for the hydrodynamic injection in the CE-UV setup $\left(\mathbf{c}^{*}\right)$. During the electrophoretic separation, the liquid levels in the inlet and outlet buffer vials were at the same level, to avoid gravity-driven flow

flow was first described by Matysik et al. [21]. The flow in the capillary was gravity-driven by a permanent height difference between the inlet and outlet carrier solution vials. We always used the term BGE instead of carrier solution because both solutions were identical. The injection time for all CFIA-C ${ }^{4}$ D experiments was $5 \mathrm{~s}$. A laboratory-constructed autosampler of a CE device was used for the hydrodynamic injection. The sample solution consisted of $10 \mathrm{mmol} / \mathrm{dm}^{3}$ $\mathrm{dMFc}$ in BGE. A high-resolution $\mathrm{C}^{4} \mathrm{D}$ was placed after $40 \mathrm{~cm}$ from the injection side for detection. The detector described elsewhere was constructed in the group of Prof. C. L. do Lago (São Paulo, Brazil) [22]. A double determination at two different heights was done for the calculation of the VFRs.

\section{CE-UV setup}

Figure 5 shows a scheme of the CE-UV setup on the right side. It consisted of a laboratory-constructed CE device with an integrated autosampler. This device was connected to a T1CP 300304 p high voltage power supply from ISEG (Radeberg, Germany). The whole CE system was placed in an acrylic glass housing for safety reasons. 


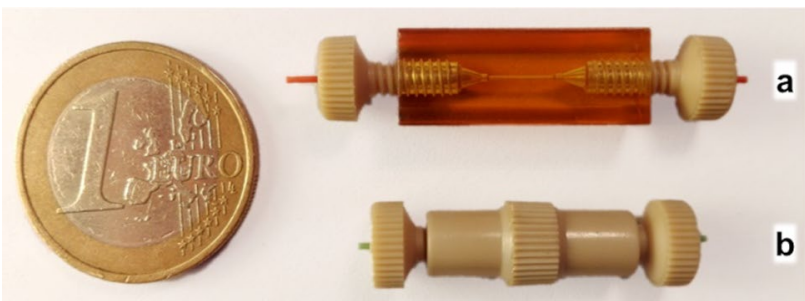

Fig. 6 Photograph of the transparent lab-built capillary connector fabricated from polyetherimide (a) and the commercially available capillary connector fabricated from polyether ether ketone (b)

The separations were carried out with non-fragmented 25,50 , and $75 \mu \mathrm{m}$ capillaries and with capillary combinations implementing a $50 \mu \mathrm{m}$ downstream capillary segment $(25+50,50+50$, and $75+50 \mu \mathrm{m})$. To find an explanation for the migration behavior also, experiments with the reverse capillary combinations were performed. In these measurements, the upstream capillary piece had an ID of $50 \mu \mathrm{m}$ and a length of $50 \mathrm{~cm}$ and the downstream capillaries had IDs of 25,50 , and $75 \mu \mathrm{m}$ and a length of $20 \mathrm{~cm}$. A Lambda 1010 UV/VIS detector from Bischoff (Leonberg, Germany) was used for detection at $210 \mathrm{~nm}$. The detector was placed after $40 \mathrm{~cm}$. A sample solution containing $1 \mathrm{mmol} / \mathrm{dm}^{3}$ $\mathrm{FcMeOH}$ and $\mathrm{dMFc}$ in BGE was utilized. The injection was performed hydrodynamically by lowering the outlet buffer vial by $20 \mathrm{~cm}$. A uniform sample plug was injected to compare band broadening effects. The injection segment had a length of $0.35 \mathrm{~cm}(0.5 \%$ of the total capillary length) and the respective injection times were determined based on the VFR of the corresponding capillary combination. For the electrophoretic separation, a separation voltage of $25 \mathrm{kV}$ was applied and the inlet and the outlet BGE vials were placed at the same height so that there was no gravity-driven flow which affected the migration behavior. Each measurement was done three times.

\section{Transparent capillary connector}

To support the results from the CE-UV measurements, the behavior of a dye segment at the connection site between two capillaries with different IDs was examined utilizing a transparent capillary connector. The lab-built capillary connector was made of polyetherimide and had a $350 \mu \mathrm{m}$ drilling. The capillary connector was additionally flattened and polished at one side for better microscope images. The lab-built capillary connector is illustrated in Fig. 6 in comparison to the commercially available capillary connector. For the experiment, a $20 \mathrm{~cm}$ piece of a $25 \mu \mathrm{m}$ and a $50 \mathrm{~cm}$ piece of a $75 \mu \mathrm{m}$ capillary were used. At the connection side of each capillary, $2 \mathrm{~cm}$ of polyimide was removed to enable visualization of the dye plug at the connection site. Both capillary segments were coupled without dead volume by means of the transparent capillary connector. The capillaries were attached with Micro Tight Nuts F 125 and with Micro Tight Sleeves F 184 from IDEX Health \& Science (Oak Harbor, USA). For the images, the connector was placed on the table of a DigiMicro Lab 5.0 microscope from dnt (Dietzenbach, Germany). A saturated methylene blue solution in BGE was used as a sample solution and BGE was used as a carrier solution. The injection was performed hydrodynamically by lowering the outlet vial and capillary flow was also generated hydrodynamically. The length of the dye segment was adjusted to about $1 \mathrm{~cm}$ corresponding to the image section of the microscope.

Acknowledgements We are grateful to the German Research Foundation (DFG) for financial support (project number MA1491/12-1).

Funding Open Access funding enabled and organized by Projekt DEAL.

Open Access This article is licensed under a Creative Commons Attribution 4.0 International License, which permits use, sharing, adaptation, distribution and reproduction in any medium or format, as long as you give appropriate credit to the original author(s) and the source, provide a link to the Creative Commons licence, and indicate if changes were made. The images or other third party material in this article are included in the article's Creative Commons licence, unless indicated otherwise in a credit line to the material. If material is not included in the article's Creative Commons licence and your intended use is not permitted by statutory regulation or exceeds the permitted use, you will need to obtain permission directly from the copyright holder. To view a copy of this licence, visit http://creativecommons.org/licenses/by/4.0/.

\section{References}

1. Ramos-Payán M, Ocaña-Gonzalez JA, Fernández-Torres RM, Llobera A, Bello-López MÁ (2018) Electrophoresis 39:111

2. Voeten RLC, Ventouri IK, Haselberg R, Somsen GW (2018) Anal Chem 90:1464

3. Beutner A, Scherer B, Matysik F-M (2018) Talanta 183:33

4. Blasco S, Kortz L, Matysik F-M (2009) Electrophoresis 30:3355

5. Beutner A, Herl T, Matysik F-M (2019) Anal Chim Acta 1057:18

6. Lapainis T, Sweedler JV (2008) J Chromatogr A 1184:144

7. Grundmann M, Matysik F-M (2012) Anal Bioanal Chem 404:1713

8. Deyl Z, Mikšík I, Charvátová J, Eckhardt A (2003) J Chromatogr A 1013:233

9. Jooß K, Hühner J, Kiessig S, Moritz B, Neusüß C (2017) Anal Bioanal Chem 409:6057

10. Kler PA, Posch TN, Pattky M, Tiggelaar RM, Huhn C (2013) J Chromatogr A 1297:204

11. Sydes D, Kler PA, Hermans M, Huhn C (2016) Electrophoresis 37:3020

12. Wei J, Gu X, Wang Y, Wu Y, Yan C (2011) Electrophoresis 32:230

13. Kohl FJ, Sánchez-Hernández L, Neusüß C (2015) Electrophoresis 36:144

14. Pavlíček V, Tůma P, Matějčková J, Samcová E (2014) Electrophoresis 35:956

15. Šebestová A, Petr J (2017) Electrophoresis 38:3124

16. Tůma P, Opekar F, Samcová E (2013) Electrophoresis 34:552 
17. Horká M, Karásek P, Roth M, Šlais K (2017) Electrophoresis 38:1260

18. Matysik F-M (1998) J Chromatogr A 802:349

19. Scholz R, Matysik F-M (2011) Analyst $136: 1562$

20. Lauer HH, Rozing GP (2018) High performance capillary electrophoresis, 2nd edn. Agilent Technologies, Germany

21. Matysik F-M, Werner G (1993) Analyst 118:1523
22. Francisco KJM, do Lago CL (2009) Electrophoresis 30:3458

Publisher's Note Springer Nature remains neutral with regard to jurisdictional claims in published maps and institutional affiliations. 